\title{
GCU
}

Glasgow Caledonian

University

University for the Common Good

\section{Development of a control system for a domestic grid-connected wind turbine}

Adamson, Michael Angus; Muhammad-Sukki, Firdaus; Abu-Bakar, Siti Hawa; Ab Aziz, Nur Fadilah; Sellami, Nazmi; lyi, Draco; Ramirez-Iniguez, Roberto; Bani, Nurul Aini; Mas Ud, Abdullahi Abubakar; Munir, Abu Bakar ; Yasin, Siti Hajar Mohd

Published in:

PACE International Conference on Science and Technology

Publication date:

2017

Document Version

Author accepted manuscript

Link to publication in ResearchOnline

Citation for published version (Harvard):

Adamson, MA, Muhammad-Sukki, F, Abu-Bakar, SH, Ab Aziz, NF, Sellami, N, lyi, D, Ramirez-Iniguez, R, Bani, NA, Mas Ud, AA, Munir, AB \& Yasin, SHM 2017, Development of a control system for a domestic grid-connected wind turbine. in PACE International Conference on Science and Technology. Penang, Malaysia, PACE International Conference on Science and Technology, 25/07/17.

\section{General rights}

Copyright and moral rights for the publications made accessible in the public portal are retained by the authors and/or other copyright owners and it is a condition of accessing publications that users recognise and abide by the legal requirements associated with these rights.

Take down policy

If you believe that this document breaches copyright please view our takedown policy at https://edshare.gcu.ac.uk/id/eprint/5179 for details of how to contact us. 


\title{
Development of a Control System for a Domestic Grid-Connected Wind Turbine
}

\author{
Michael Angus Adamson 1,2, Firdaus Muhammad-Sukki 2,*, Siti Hawa Abu-Bakar², Nur Fadilah Ab Aziz , \\ Nazmi Sellami ${ }^{2}$, Draco Iyi ${ }^{2}$, Roberto Ramirez-Iniguez ${ }^{5}$, Nurul Aini Bani ${ }^{6}$, Abdullahi Abubakar Mas'ud ${ }^{7}$, \\ Abu Bakar Munir ${ }^{8}$, Siti Hajar Mohd Yasin ${ }^{9}$ \\ ${ }^{1}$ Forster Energy, Scotland, United Kingdom \\ ${ }^{2}$ School of Engineering, Robert Gordon University, Scotland, United Kingdom \\ ${ }^{3}$ Universiti Kuala Lumpur British Malaysian Institute, Selangor, Malaysia \\ ${ }^{4}$ Department of Electrical Power Engineering, College of Engineering, Universiti Tenaga Nasional, Selangor, Malaysia \\ ${ }^{2}$ School of Engineering and Built Environment, Glasgow Caledonian University, Scotland, United Kingdom \\ ${ }^{6}$ UTM Razak School of Engineering and Advanced Technology, Universiti Teknologi Malaysia Kuala Lumpur, Malaysia \\ ${ }^{7}$ Department of Electrical and Electronic Engineering Technology, Jubail Industrial College, Saudi Arabia \\ ${ }^{8}$ Faculty of Law, University of Malaya, Kuala Lumpur, Malaysia \\ ${ }^{9}$ Faculty of Law, Universiti Teknologi MARA, Selangor, Malaysia \\ *f.b.muhammad-sukki@rgu.ac.uk
}

\begin{abstract}
In the United Kingdom (UK), homeowners who install grid connected renewable energy sources receive a threefold benefit. They can use the electricity generated by the source, they enjoy reduced household bills and they can also receive Feed-in Tariff payments from the UK government. Tariffs are paid for generating electricity and for exporting electricity back to the grid. Savings can be maximised by correctly managing the ratio of number of units consumed by the homeowner to the number of units exported to the grid. In order to achieve a low percentage export situation, it was postulated that a control system would be needed. This paper proposed a control system for a small wind turbine based on an Arduino Uno microcontroller. The system was designed and built in order to evaluate its effectiveness. Results showed that the control system was effective in ensuring a low percentage export. When immediate domestic demand was met, surplus electricity was diverted to a storage circuit. Only as a last resort, when domestic and storage demand was met, was electricity exported. A cost analysis of the system showed that having a control system incorporated as part of the wind turbine installation could lead to savings of more than $£ 12,000$ over the life of the product.
\end{abstract}

Index Terms - Arduino Uno microcontroller, control system, feed-in tariff, wind turbine.

\section{INTRODUCTION}

The Feed-in Tariff (FIT) scheme was introduced by the United Kingdom (UK) government in April 2010 to encourage greater numbers of small/medium renewable electricity installations [1]. The scheme has been remarkably successful as the total installed capacity (TIC) of FIT eligible schemes in the UK has grown from 45MW across 9,500 installations in April 2010 to over $4.6 \mathrm{GW}$ across 850,000 installations in January 2016 [2].

The scheme operates by paying fixed "tariffs" to the owners of eligible installations based on the number of units of electricity generated and exported. The size of the tariff depends on the size and type of installation. The Department of Energy \& Climate Change (DECC) sets an annual spend cap for tariffs paid to newly deployed installations, which they are aiming to reduce to $£ 100 \mathrm{~m}$ per year by the end of 2018 [3], [4], a decrease of $72.2 \%$ on the $£ 360 \mathrm{~m}$ paid out in 2012 [5]. This has led to steady cuts to the tariff prices across all size and technology categories. One of the categories worst affected by these tariff cuts is the small wind category (1.5 $15 \mathrm{~kW}$ ). Deployment rates fell $73 \%$ in 2013 as a result of tariff cuts and have never recovered [2].

Despite tariff prices falling to the values shown in Table 1, small wind power is still considered by some a viable method of renewable electricity generation. This is especially true in areas such as the north-east coast of Scotland and outlying Scottish islands (Hebrides, Orkney and Shetland). The Shetland Islands, for example, have an average wind speed of $22 \mathrm{mph}$ which is double the national average [6]. It is important, therefore, that customers in these areas - or indeed any area - have good knowledge of the FIT scheme and how to take advantage of it in order to obtain the maximum economic benefits their systems can provide.

Under the FIT scheme terms a homeowner has two options for any power generated by their system; consume it domestically or export it to the grid. A tariff is paid for every unit of electricity generated, regardless of whether it is consumed or exported. An additional tariff is paid for every unit of electricity exported. It is, however, impossible for

Table 1: Wind Tariffs 8th Feb - 31st March 2016 [5].

\begin{tabular}{lc}
\hline Description & $\begin{array}{c}\text { Tariff } \\
\text { (pence/ } \\
\text { unit) }\end{array}$ \\
\hline Wind with total installed capacity of $50 \mathrm{~kW}$ or less & 8.53 \\
$\begin{array}{l}\text { Wind with total installed capacity greater than } 50 \mathrm{~kW} \text { but } \\
\text { not exceeding } 100 \mathrm{~kW}\end{array}$ & 8.53 \\
$\begin{array}{l}\text { Wind with total installed capacity greater than } 100 \mathrm{~kW} \text { but } \\
\text { not exceeding } 1.5 \mathrm{MW}\end{array}$ & 5.46 \\
$\begin{array}{l}\text { Wind with total installed capacity exceeding } 1.5 \mathrm{MW} \\
\text { Export tariff }\end{array}$ & 0.86 \\
\hline \hline
\end{tabular}


electricity suppliers to measure the number of units exported unless the installation is fitted with a smart meter. There is no current obligation for homeowners to have a smart meter fitted unless their installation has a TIC greater than $30 \mathrm{~kW}$, although the government wants them fitted as standard by 2020 [7]. Suppliers, therefore, "deem" the number of units exported to be $50 \%$ of the number generated and pay the export tariff accordingly, regardless of the actual amount exported [8].

If the homeowner is exporting less than $50 \%$ of what they generate, they are coming ahead twofold. They are being paid an export tariff for electricity they are not exporting plus they get the benefit of using that electricity and reducing their household bills. Obviously then, the ideal situation is to export $0 \%$ of what is generated. Though this is usually unfeasible in practice as there will be times during the day when domestic demand is low and electricity is still being generated.

To reduce exports then, a method of effectively using the electricity generated during these periods must be devised. A good way of doing this is to interface with other domestic systems. This "excess" electricity can be used to power immersion heaters in a domestic hot water tank, electric under-floor heating or panel heaters. In order to do this a control system is needed. It should monitor generation levels, determine which circuits receive power under different wind conditions and manage the diversion of excess electricity to each circuit.

This paper aims at developing a control system which can make effective use of excess wind-generated electricity throughout the house. The control system should ensure that, as far as possible, excess electricity is used by secondary circuits as part of other domestic systems within the house in order to achieve maximum savings for the homeowner.

\section{DESIGN APPROACH}

Initial design was done at a high level, identifying key features constraints of the system and project constraints. Creating a high level design allowed the system to be broken down into smaller subsystems which could then be looked at individually. The following features were identified as essential to the operation of the system: wind turbine supply, grid supply, domestic load, storage load, power measurement, microcontroller, load switching circuitry and LCD Module.

\section{A. Project Constraints}

When carrying out initial design work, constraints which could affect any aspect of the project were identified so that the system was built to an appropriate specification. Constraints were classified under three headings; safety, availability of resources and cost.

\section{(1) Safety:}

- No use of mains voltage. There is an obvious risk of electrocution when working with mains voltages and as such this was not a possibility. A safe low voltage source was used instead to simulate a grid voltage.

(2) Availability of Resources:

- Electronic components - such as resistors, relays, light emitting diodes (LED), switches, connectors - wiring and tools were all available from the university. Printed circuit boards (PCB) could be produces by the university technicians. An Arduino Uno microcontroller from the university stock was available for use in this project.

- As time was also a limited resource, only one additional circuit was designed; called the storage circuit.

(3) Cost:

- The budget for the project was $£ 100$. Items sourced which the university could not provide were a suitable wind turbine and an LCD module.

In light of the project constraints the design approach had to change. Due to the restrictions on using mains voltage, it was decided to use a $5 \mathrm{~V}$ DC power supply to simulate the grid. This was done as the university could provide breadboard units with built in 5V DC supplies. This change to a low voltage DC supply had an effect on other parts of the system.

It had an effect on the power conditioning system for the wind turbine as an inverter was no longer required. It was still possible to carry out maximum power point tracking (MPPT) using a boost converter but cost was prohibitive to this as many MPPT controllers were out with the budget of the project. The decision was taken just to use a simple variable DC voltage for the input from the wind turbine. This could be done from a variable DC power supply for testing purposes.

Another effect it had was on the system's ability to measure power. Surplus power is measured by the use of a current transformer on the main power line in from the grid. However, current transformers (CTs) require AC current to operate and so this method of power measurement could not work with the 5V DC supply. It was decided that instead of detecting when surplus power was being produced, the system would start diverting to the storage circuit once a certain voltage was being produced by the wind turbine.

With these revisions in mind a system block diagram was created, as presented in Figure 1.

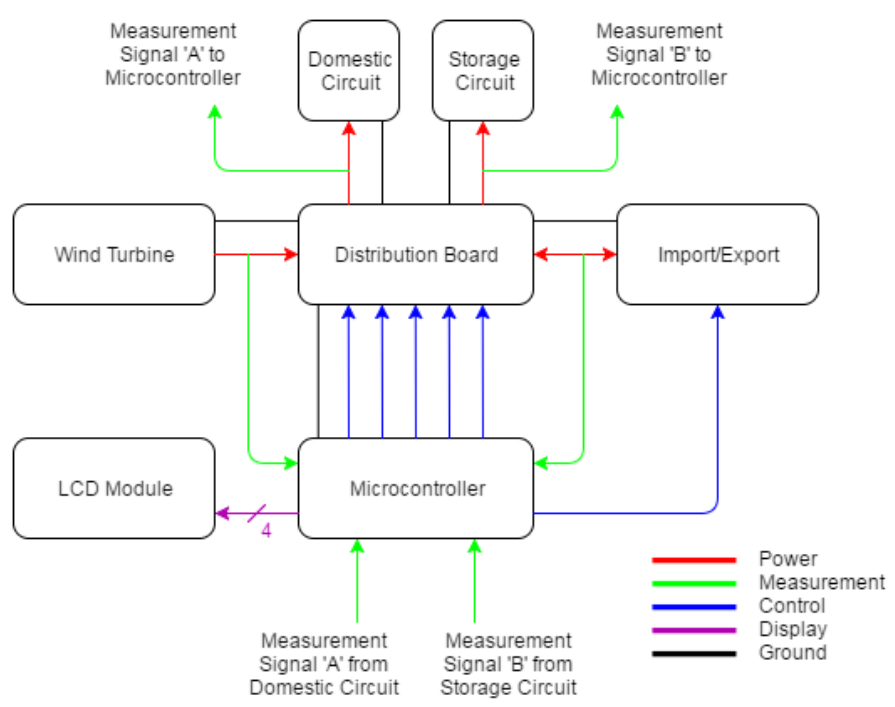

Figure 1: System Block Diagram. 


\section{B. Subsystems}

The design of each subsystem shown in Figure 1 will now be described in detail.

\section{Wind Turbine}

As already stated a variable DC power supply was used to simulate the wind turbine voltage under test conditions. However, for demonstration purposes a small DC wind turbine was sourced. The turbine ordered was a KidWind MINI Wind Turbine [9], which had a typical output of $1-4$ volts [10]. The turbine is shown in Figure 2.

Power and ground connections were made between the wind turbine and distribution board. The power wire was also connected to the microcontroller to allow the wind turbine voltage to be measured. This was so microcontroller could determine when the turbine voltage was high enough to switch on the storage circuit.

\section{Import/Export}

The function of this subsystem was to simulate the grid. It was to act as a power supply to the distribution board when importing and act as a load when exporting. When importing, power would be provided by a fixed $5 \mathrm{~V}$ DC breadboard supply. The export load was simulated by an LED in series with a resistor.

In order to allow the subsystem to have this dual functionality, a method of switching between the import and export circuits was needed. This was achieved through the use of a double throw relay. The normally closed (NC) contact was connected to the import supply and the normally open contact (NO) was connected to the export load. The fixed terminal of the relay was connected to the distribution board. When importing was taking place, the relay coil was left deenergised so that current could flow from the power supply to the distribution board through the $\mathrm{NC}$ contact. When exporting was taking was taking place, the relay coil was energised by a control signal from the microcontroller so current could flow from the distribution board to the export load through the NO contact. Exporting only took place after the domestic and storage circuits had been supplied.

The relays supplied by the university were Goodsky GSSH-205T double pole double throw (DPDT) relays. The coil voltage of these relays was $5 \mathrm{~V}$ which meant they could be switched directly from the Arduino digital output pins.

Figure 3 shows a measurement signal taken from the export load. The voltage at that point in the circuit and the value of the resistor was used to calculate the current flowing in the

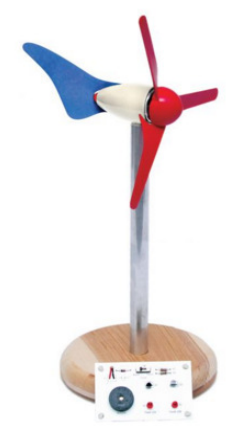

Figure 2: KidWind MINI Wind Turbine [9].

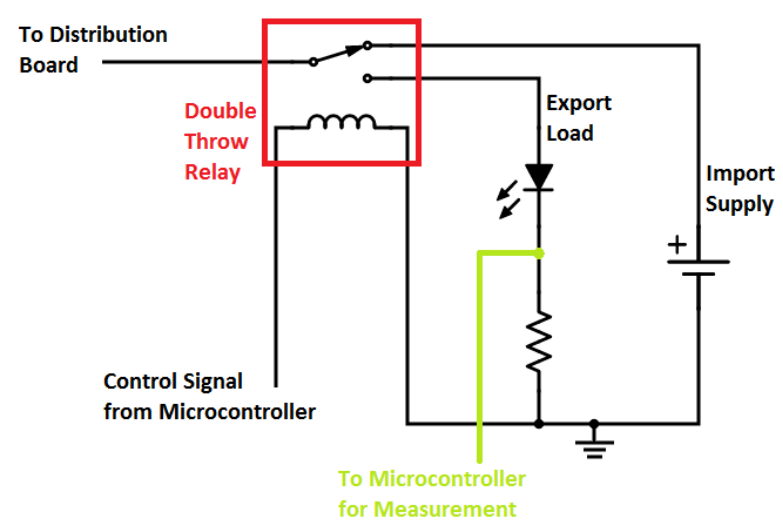

Figure 3: Import/Export Circuit Diagram.

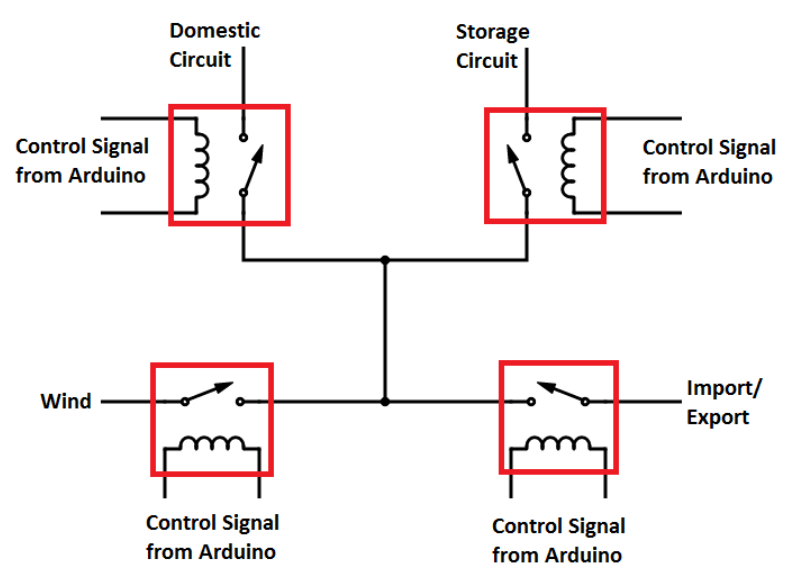

Figure 4: Distribution Board Circuit Diagram.

export load. This computation was done in software on the Arduino. An $820 \Omega$ resistor was used to ensure the current flowing through the Kingbright $5 \mathrm{~mm}$ Red LED was less than the maximum of $30 \mathrm{~mA} \mathrm{[11].}$

\section{Distribution Board}

The first purpose of the distribution board shown in Figure 4 was to handle the interface between the wind turbine supply and the import supply. It was possible for both the turbine and the grid to feed the domestic circuit at the same time under certain loading conditions. However, due to the constraints in place for the simulated system, this was no longer the case. The principle of both supplies feeding at the same time hinged on the fact that both supplies had the same voltage. As the wind turbine produced a variable voltage, it meant only one supply could feed the domestic circuit at any one time and the other had to remain isolated. If both supplies were connected at the same then the one with the higher voltage would supply the whole load, thus defeating the purpose of dual feeding. As a result, the Arduino determined which power source to use based on the voltage measurement taken from the wind turbine.

The interface between the two supplies was implemented using Goodsky relays which were switched by the Arduino digital pins. There were two possible configurations; a one relay solution or a two relay solution. After consideration, it was decided that the two relay solution was the better design 
option. This was due to a combination of factors. Firstly it allowed for the load circuits to be completely isolated from both power supplies, whereas the one relay solution did not. This is much more like a full scale domestic system which has isolators at the turbine inverter and the consumer unit, thus making the system much safer. Secondly, the two relay solution was more suited to future developments. If at some point the system was modified to enable dual feeding of the load, the two relay solution could be used to facilitate this, whereas the one relay solution could not. The relays were switched from the Arduino digital pins.

The other purpose of the distribution board was to switch the domestic and storage circuits as and when required. This was again done using Goodsky relays which would be switched by the Arduino digital output pins. It ensured that the storage circuit was only used when a certain voltage level was reached by the wind turbine. This will be discussed in greater detail in the microcontroller subsystem section.

\section{Domestic and Storage Circuits}

Simple loads were devised for both the domestic and storage circuits as shown in Figure 5. Both circuits were modelled as a simple series branch containing a resistor and an LED. The LEDs used were Kingbright $5 \mathrm{~mm}$ Green LEDs with a maximum operating current of $25 \mathrm{~mA}$ [11]. Resistance values well above the $R_{\text {minimum }}$ were chosen to ensure the LEDs were never operating near their maximum current limit. Different values were deliberately chosen to simulate a difference in load size between the two circuits where $\mathrm{R}_{\text {domestic }}$ and $\mathrm{R}_{\text {storage }}$ is chosen to be $330 \Omega$ and $680 \Omega$ respectively.

The voltage across both resistors was measured by the Arduino to allow the load current in each branch to be calculated. This would be useful to know for a consumer as they could see the amount of electricity being diverted to their storage circuit, which would otherwise have been exported.

\section{Microcontroller}

\section{Hardware Configuration}

An Arduino Uno was chosen as the microcontroller for the system. Figure 6 shows the location of all the pins on the Arduino. Table 2 gives information about the function of each pin; including what it was connected to and whether it acted as an input or an output. In the "Assertion" column it also shows what type of signal each pin produced or received and what that represented.

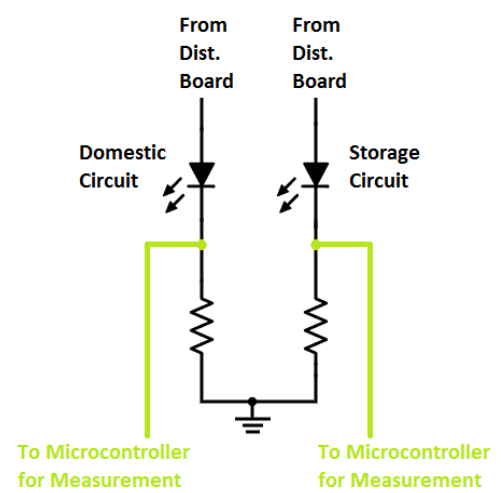

Figure 5: Domestic and Storage Loads Circuit Diagram.

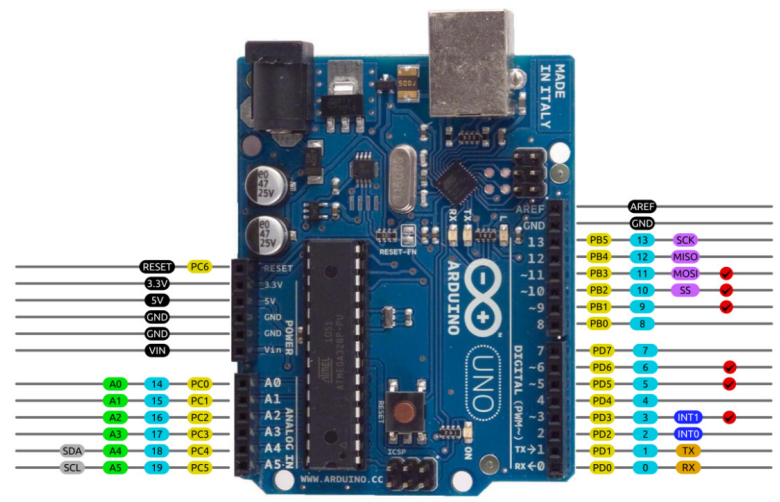

AVR DIGITAL ANALOG POWER SERIAL SPI I2C PWM INTERRUPT

Figure 6: Arduino Uno Pinout [12].

Table 2: Arduino Pinout.

\begin{tabular}{|c|c|c|c|}
\hline Pin & Type & Use & Assertion \\
\hline D0 & $\mathrm{N} / \mathrm{A}$ & Not Connected & N/A \\
\hline D1 & N/A & Not Connected & N/A \\
\hline D2 & Output & $\begin{array}{c}\text { Switch the } \\
\text { Domestic Circuit }\end{array}$ & $\begin{array}{c}\text { High }=\text { Closed } \\
\text { Low }=\text { Open }\end{array}$ \\
\hline D3 & Output & $\begin{array}{l}\text { Switch the } \\
\text { Storage Circuit }\end{array}$ & $\begin{array}{c}\text { High }=\text { Closed } \\
\text { Low }=\text { Open }\end{array}$ \\
\hline D4 & Output & $\begin{array}{c}\text { Switch the } \\
\text { Import/Export } \\
\text { Circuit }\end{array}$ & $\begin{array}{l}\text { Low = Import, } \\
\text { High = Export }\end{array}$ \\
\hline D5 & Input & $\begin{array}{l}\text { Push Button } 1 \text { for } \\
\text { LCD Module }\end{array}$ & $\begin{array}{c}\text { High }=\text { Button Pressed } \\
\text { Low }=\text { Button Not Pressed }\end{array}$ \\
\hline D6 & Input & $\begin{array}{l}\text { Push Button } 2 \text { for } \\
\text { LCD Module }\end{array}$ & $\begin{array}{c}\text { High }=\text { Button Pressed } \\
\text { Low }=\text { Button Not Pressed }\end{array}$ \\
\hline D7 & Input & $\begin{array}{l}\text { Push Button } 3 \text { for } \\
\text { LCD Module }\end{array}$ & $\begin{array}{c}\text { High }=\text { Button Pressed } \\
\text { Low }=\text { Button Not Pressed }\end{array}$ \\
\hline D8 & Input & $\begin{array}{l}\text { Push Button } 4 \text { for } \\
\text { LCD Module }\end{array}$ & $\begin{array}{c}\text { High }=\text { Button Pressed } \\
\text { Low }=\text { Button Not Pressed }\end{array}$ \\
\hline D9 & Output & $\begin{array}{c}\text { Connect Wind } \\
\text { Supply to Dist. } \\
\text { Board }\end{array}$ & $\begin{aligned} \text { High } & =\text { Closed } \\
\text { Low } & =\text { Open }\end{aligned}$ \\
\hline D10 & Output & $\begin{array}{l}\text { Connect } \\
\text { Import/Export to } \\
\text { Dist. Board }\end{array}$ & $\begin{aligned} \text { High } & =\text { Closed } \\
\text { Low } & =\text { Open }\end{aligned}$ \\
\hline D11 & N/A & Not Connected & N/A \\
\hline D12 & N/A & Not Connected & N/A \\
\hline D13 & N/A & Not Connected & N/A \\
\hline A0 & Input & $\begin{array}{l}\text { Wind Voltage } \\
\text { Measurement } \\
\text { Domestic }\end{array}$ & $0-5 \mathrm{~V}$ \\
\hline A1 & Input & $\begin{array}{c}\text { Voltage } \\
\text { Measurement }\end{array}$ & $0-5 \mathrm{~V}$ \\
\hline $\mathrm{A} 2$ & Input & $\begin{array}{l}\text { Storage Voltage } \\
\text { Measurement }\end{array}$ & $0-5 \mathrm{~V}$ \\
\hline A3 & Input & $\begin{array}{l}\text { Export Voltage } \\
\text { Measurement }\end{array}$ & $0-5 \mathrm{~V}$ \\
\hline $\begin{array}{c}\mathrm{A} 4 \\
(\mathrm{SDA})\end{array}$ & Output & $\begin{array}{l}\text { Serial Data Line } \\
\text { for LCD Module }\end{array}$ & Digital Data Stream \\
\hline $\begin{array}{c}\mathrm{A} 5 \\
(\mathrm{SCL})\end{array}$ & Output & $\begin{array}{l}\text { Serial Clock Line } \\
\text { for LCD Module }\end{array}$ & Digital Clock \\
\hline $5 \mathrm{~V}$ & Supply & $\begin{array}{l}\text { Power to LCD } \\
\text { Module }\end{array}$ & $5 \mathrm{~V}$ \\
\hline GND & Supply & $\begin{array}{l}\text { Ground to LCD } \\
\text { Module }\end{array}$ & $0 \mathrm{~V}$ \\
\hline GND & Supply & $\begin{array}{l}\text { Common Ground } \\
\text { to Dist. Board }\end{array}$ & $0 \mathrm{~V}$ \\
\hline
\end{tabular}

A common ground connection was made from the Arduino to the distribution board using one of the $0 \mathrm{~V}$ pins on the 
Arduino. This was to ensure that all measurements were taken to the same $0 \mathrm{~V}$ reference throughout the system.

Power to the Arduino was to be provided by a computer via the Arduino's on-board USB connection.

\section{Software Structure}

In the Distribution Board section it was discussed how the turbine and grid could not supply the load simultaneously due to the voltage levels being different. Instead the grid would supply the domestic load until the voltage produced by the wind turbine reached a certain threshold, T1. At that point the Arduino would assert pin D9 "high" and pin D10 "low" to feed the domestic circuit from the wind turbine.

In the System Constraints section it was discussed how the system could not measure power. Instead the system would start diverting to storage based on depending on the voltage produced by the wind turbine. If, after $\mathrm{T} 1 \mathrm{had}$ been reached, the wind voltage kept increasing, it would reach the diversion threshold, T2. At that point the Arduino would assert pin D3 "high" to start feeding the storage circuit. If the wind voltage kept rising further, it would reach the export threshold, T3. At that point the Arduino would assert pin D4 "high" to switch from import to export. It would also assert pin D10 "high" to connect the distribution board to the Import/Export subsystem and allow the turbine to feed the export circuit. The whole process happened in reverse when the wind turbine voltage started to decrease. The process is better demonstrated by the flowchart in Figure 7.

Another purpose of the Arduino was to calculate the current flowing in each load branch. This was done in code using the measured voltage across the resistor in each branch and the corresponding resistor value. The current values as well as the measured wind turbine voltage were sent to the LCD module to be displayed to the user.

\section{LCD Module}

The LCD Module selected was a Blue Serial I2C 2004A with a 20x4 character display. The LCD module displayed system data passed to it by the Arduino. For clarity, all data was not displayed on the screen at one time. A menu system was employed, which allowed the user to select which data to view by pressing different input buttons. The main menu presented the user with the choice of two of submenus. The wind turbine voltage was displayed in submenu 1 and the system load currents were displayed in submenu 2 . These were accessed by pressing buttons ' 1 ' and ' 2 ' respectively on the input pad. Button ' 4 ' was used to return to the main menu. Button ' 3 ' was reserved for future expansions of the system.

Data was passed to from the Arduino to the LCD module via the I2C serial bus. The bus was accessed through analog pins A4 and A5, also called Serial Data (SDA) and Serial Clock (SCL). Power was provided to the LCD module via the $5 \mathrm{~V}$ and $0 \mathrm{~V}$ pins on the Arduino. Communications on the $\mathrm{I} 2 \mathrm{C}$ bus were handled by two libraries. The first was an in-built library in Arduino firmware called "Wire.h". The second was an open source library called "LiquidCrystal_I2C.h" and was developed by Fdebrabander [13] - a user of the Github programming community.

The input pad worked by sending digital "high" or "low" signals to the Arduino digital input pins to indicate if a button had been pressed or not. The switches used were "push-tomake" and as such were normally open (NO). In this state the

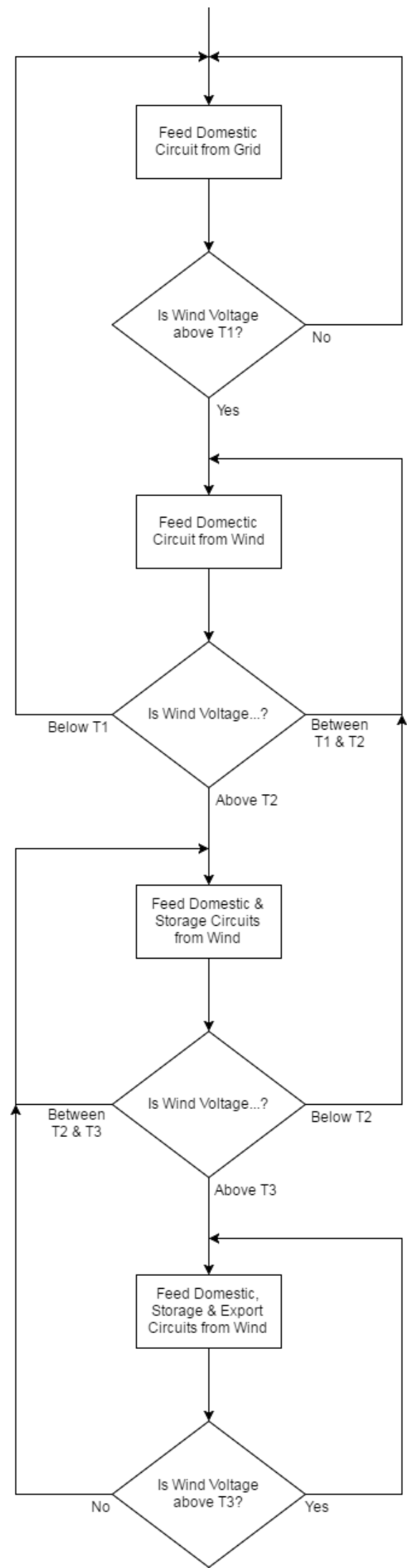

Figure 7: Arduino Program Flowchart. 
input pins were connected to $0 \mathrm{~V}$ using a pull-down resistor. When the switch was pressed, the pins were connected to the power supply feeding the load at that time. High value pulldown resistors $(15 \mathrm{k} \Omega$ ) were used so as to draw minimal current through the switches.

\section{Testing AND Results’ Discussion}

Testing was carried out on a breadboard first prior to manufacture. This allowed issues such as the necessity for pull-down resistors on the input pad to be identified. The design was then changed to remedy these issues before the final system was manufactured. Figure 8 below shows the finished system. The final system was tested with successful results demonstrated and recorded.

Prior to carrying out the test, the threshold values were chosen as $\mathrm{T} 1=3.6 \mathrm{~V}, \mathrm{~T} 2=4.0 \mathrm{~V} \& \mathrm{~T} 3=4.4 \mathrm{~V}$ for reasons described in section 4.1.5. As shown by the results of testing these values worked well, however it did raise an issue. When the turbine voltage lay between these values the system operated as expected, but when the turbine voltage lay on or around these thresholds the system would flicker very quickly from one state to another. Circuits were switched on and off very quickly. This could damage the switchgear as well as the loads. In order to reduce this effect, hysteresis was added to the system. Saini [14] defines hysteresis as "the time-based dependence of a system's output on current and past inputs". This method was implemented in the control system where $\mathrm{T} 1+$ was set to $0.05 \mathrm{~V}$ above $\mathrm{T} 1(3.65 \mathrm{~V})$ and $\mathrm{T} 1$ - was set to $0.05 \mathrm{~V}$ below $\mathrm{T} 1(3.55 \mathrm{~V})$. This meant that only fluctuations in turbine voltage of greater than $0.1 \mathrm{~V}$ could turn circuits on and off. The same thing was done for $\mathrm{T} 2$ and $\mathrm{T} 3$. When tested, this removed the problem of rapid circuit switching, thus preserving the system.

A shortcoming of the system was highlighted during this test. This was the changeover between grid feeding and wind feeding. As the grid supply is $5 \mathrm{~V}$ and the changeover threshold from grid to wind (T1) is set to $3.6 \mathrm{~V}$, there is a voltage drop every time the wind supply cuts in. The domestic LED gets noticeably dimmer at this transition, which is clearly undesirable. However, while this is an issue in this system, it would not be an issue in a full size system. This is because the

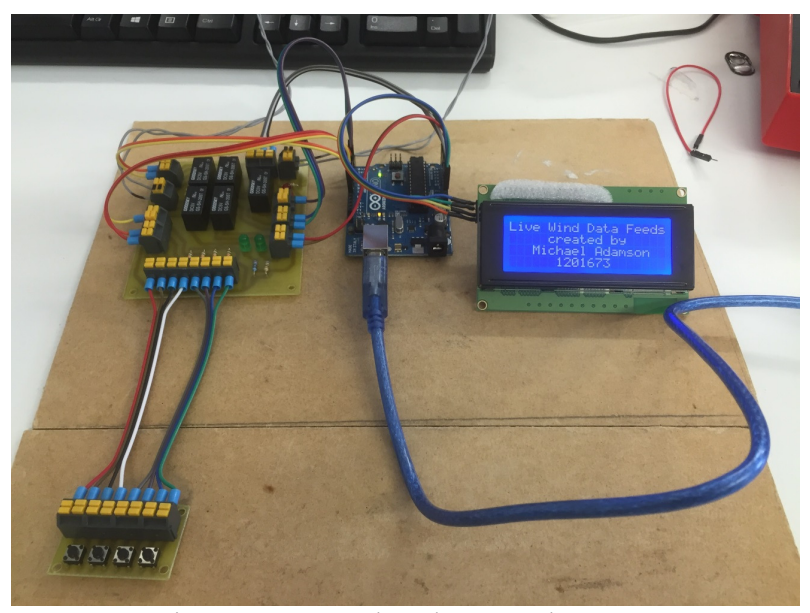

Figure 8: Completed Control System.
Table 3: Installation Cost \& Tariff Comparison.

\begin{tabular}{ll}
\hline \hline Item & March 2016 \\
\hline Installation Cost & $£ 27,612.10$ \\
Groundworks & $£ 5,000$ \\
Thermal Heatstore & $£ 7,000$ \\
Generation Tariff & $8.53 \mathrm{p} / \mathrm{kWh}$ \\
Export Tariff & $4.85 \mathrm{p} / \mathrm{kWh}$ \\
Electricity Units Generated in First Year & $26290 \mathrm{kWh}$ \\
Electricity Units Saved By immerSUN in & $12912 \mathrm{kWh}$ \\
First Year & \\
\hline \hline
\end{tabular}

Table 4: Utility Usage Data and Cost Information (Provided by Nordri Ltd.'s Customer)

\begin{tabular}{lcc}
\hline \hline Item & $\begin{array}{c}\text { With } \\
\text { Controller }\end{array}$ & $\begin{array}{c}\text { Without } \\
\text { controller }\end{array}$ \\
\hline Electricity Units Imported from Grid (kWh) & 949 & 3935 \\
Heating Oil Units Used (litres) & 466 & 1280 \\
\hline \hline
\end{tabular}

grid and turbine would both be supplying power at the same voltage. There would also not be the same switchover moment as, in a full scale system, the wind turbine and grid can dual feed the load.

Due to time constraints, the system was never tested using the KidWind MINI Wind Turbine, but rather always with the variable breadboard power supply.

It is imperative to mention that despite the constraints in place, the design did not actually differ too much from that of an actual control system. The only major difference was what controlled the diversion of electricity to storage circuits. In an actual system, it is a current measured on the grid side of the controller, whereas in this system it was a voltage measured on the turbine side of the controller. It would not actually be too difficult to modify the existing control system to suit a conditioned $\mathrm{AC}$ wind turbine input and a mains grid connection. In both cases only a single wire connection to the microcontroller is needed in order to determine when to start diverting. All that is needed is to replace the turbine voltage measurement wire with a CT attached to the grid supply. The Arduino program could be modified accordingly to set the new diversion threshold.

Apart from this the rest of the design is broadly similar to an actual control system, with only slight differences remaining. Instead of measuring the voltage across the domestic, storage and export loads, the amount of power consumed by each circuit would be calculated. This could be done using by CTs to measure the current being drawn by each load and then performing calculations in software. Alternatively miniature wattmeters could be built into each circuit. The "System Currents" submenu on the LCD module could then be replaced by a "System Power" submenu.

\section{Cost Analysis}

In order to clearly demonstrate the benefits of having such a control system as part of a renewable energy installation, a cost analysis was carried out using data from an actual system. Data was provided by Nordri Ltd. and one of their customers (see Tables 3 and 4).

The system in question was installed in Shetland in March 2016. It comprised a Kingspan KW6 6kW Wind Turbine and a 4eco immerSUN Controller. Immersion heaters in the 
domestic hot water tank were used as the first storage circuit. Immersion heaters in a thermal heatstore were used as the second storage circuit. Electric panel heaters were used as the third storage circuit.

Prior to wind turbine installation, an oil fired boiler was used to supply the customer's central heating and domestic hot water. However after installation, the domestic hot water could be heated directly from surplus from the turbine. If no surplus was instantly available, the thermal heatstore could heat both the domestic hot water and central heating supply; providing the heatstore was up to temperature. If no surplus was available and the thermal heat store was cold, the oil fired boiler could be used as a backup.

Nordri provided a quote for a new installation under 2016 prices. Nordri quote the system as being "theoretically zero export". As such, it is assumed the data provided was measured under zero export conditions. All calculations in subsequent sections are based on this assumption. Calculations are also based on the current market prices for electricity and heating oil. This was done so as to only measure the financial impact of the turbine system and not of variation in utility price. Electricity supplier Scottish \& Southern Energy [15] quotes the tariff comparison rate (TCR) for the customer's location as $15.62 \mathrm{p} / \mathrm{kWh}$. Heating oil supplier Scottish Fuels [16] quote the price of heating oil delivered to the customer as $38 \mathrm{p} /$ litre.

FIT payments last for 20 years and are paid at the same rate every year [3], but the lifespan of a Kingspan KW6 is 25 years [17]. So in years $21-25$ the customer will not receive generation and export tariffs but will still benefit from reduced electricity and heating oil bills. It is assumed that wind generation is constant for every year of the turbine's life.

The data from Tables 3 and 4, the income, expenditure and resultant savings for the years before and after the installation were calculated and are shown in Table 5. Figure 9 is plotted, showing that the whole system will pay for itself in just 9 years, and total savings at the end of the turbine's life would be over $£ 57,000$.

Now, the system is compared with data was compared against another system that does not have the immerSUN and thermal heatstore in place. Firstly, using the cost of the controller and thermal heatstore from Table 3, the cost of installation would be reduced by $£ 7000$. Table 3 also states that the immerSUN controller saved $12,912 \mathrm{kWh}$ of electricity in the first year after installation. Without the immerSUN, this electricity would have been exported. Taking 12,912 as a percentage of the total generated - 26,290 - gives the export rate of the system to be $49.11 \%$. This percentage was again used as a proportion of the difference in grid imports and heating oil used from the years before and after installation to calculate the values shown in Table 4. Assuming wind generation was constant again, the new values for grid imports and heating oil consumed were used to calculate the total savings over the life of the turbine. These are shown in Table 6.

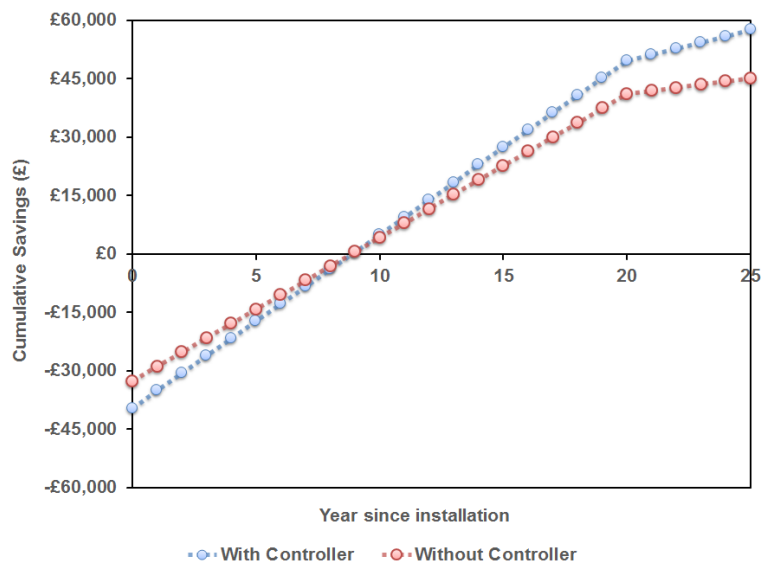

Figure 9: Cumulative savings with and without the controller in place.

Table 5: Utility Usage Data and Cost Information for System with Controller (Provided by Nordri Ltd.'s Customer)

\begin{tabular}{lccccc}
\hline \hline Item & No. of Units & \multicolumn{2}{c}{ Year 1-20 } & \multicolumn{2}{c}{ Year 21-25 } \\
& & Unit Price (pence) & Subtotal & Unit Price (pence) & Subtotal \\
\hline Grid Imports (kWh) & 949 & -15.62 & $-£ 148.23$ & -15.62 & $-£ 148.23$ \\
Heating Oil Used (Litres) & 466 & -38.00 & $-£ 177.08$ & -38.00 & $-£ 177.08$ \\
& & & & \\
Wind Generation (kWh) & 26,290 & 8.53 & $£ 2,242.54$ & 8.53 & $£ 0.00$ \\
Deemed Exports @ 50\%(kWh) & 13,145 & 4.85 & $£ 637.53$ & 4.85 & $£ 0.00$ \\
Total Income & & & $£ 2,554.76$ & & $-£ 325.31$ \\
& & & $-£ 1,904.67$ & & $-£ 1,904.67$ \\
Income Before Install & & $£ 4,459.43$ & & $£ 1,579.36$ \\
Savings (per Annum) & & &
\end{tabular}

Table 6: Utility Usage Data and Cost Information for System without Controller (Provided by Nordri Ltd.'s Customer)

\begin{tabular}{lccccr}
\hline \hline Item & \multirow{2}{*}{ No. of Units } & \multicolumn{2}{c}{ Year 1-20 } & \multicolumn{2}{c}{ Year 21-25 } \\
& & Unit Price (pence) & Subtotal & Unit Price (pence) & Subtotal \\
\hline Grid Imports (kWh) & 3,935 & -15.62 & $-£ 614.65$ & -15.62 & $-£ 614.65$ \\
Heating Oil Used (Litres) & 1,280 & -38.00 & $-£ 486.80$ & -38.00 & $-£ 486.40$ \\
& & & & & \\
Wind Generation (kWh) & 26,290 & 8.53 & $£ 2,242.54$ & 8.53 & $£ 0.00$ \\
Deemed Exports @ 50\% (kWh) & 13,145 & 4.85 & $£ 637.53$ & 4.85 & $-£ 1,101.05$ \\
Total Income & & & $£ 1,779.02$ & & $-£ 1,904.67$ \\
Income Before Install & & & & \\
Savings (per Annum) & & & $-£ 1,904.67$ & & $£ 803.62$ \\
\hline \hline
\end{tabular}


The additional information is also presented in Figure 9 to compare the difference in savings made between a controlled and uncontrolled system. Even though with the controller there is the extra initial outlay of $£ 7,000$ for the storage system, both systems break even after 9 years. The controlled system actually starts to come ahead of the uncontrolled system within 10 years of installation. Over the course of the 25 year lifespan of the turbine, a customer would save an extra $£ 12,393.33$ by using an automatic power diverting controller as part of their wind turbine installation.

\section{CONCLUSION}

An automatic power control system was designed, built and tested for domestic grid-connected wind turbine. This was done using an Arduino Uno as well as dedicated hardware. Safety and cost constraints imposed on the project meant that the system had to be implemented on a microelectronic scale. This meant some modifications had to be made to the design in terms of power supply and measurement systems. A modular approach to design was taken which allowed the system to be broken down into smaller subsystems which could be designed more manageably. The system was designed with future expansion in mind, as demonstrated by the fact that the Arduino had spare digital pins and the LCD input pad had a spare push button. Testing was carried out on a breadboard first prior to manufacture. This allowed issues such as the necessity for pull-down resistors on the input pad to be identified. The design was then changed to remedy these issues before the final system was manufactured. The final system was tested with successful results demonstrated.

A cost analysis was undertaken to determine the savings on offer to a homeowner using the system. This was done using the data from the turbine Nordri installed in Shetland in March 2016, along with the 2016 tariffs and utility prices for the most up to date results. With all relevant assumptions made, it was estimated adding an automatic power control system to an installation could save a homeowner $£ 12,393.33$ over the course of the life of the turbine. As the installation analysed in this paper was installed in Shetland (the windiest place in the UK), the savings on offer by using an automatic power control system did not actually affect the economic feasibility of such an installation. However, in a less windy location where less power would be generated, savings of $£ 12,393.33$ over a 25 year period may be the difference between a system being financially viable or not.

It is recommended to implement the system on a full-size level using mains voltages and real loads. Even without implementing on a larger scale there are still a number of improvements that could be made. The system could be mounted in an enclosure to create a more polished final product. Another improvement would be to develop the LCD module and input pad to allow the adjustment of flow priorities and diversion thresholds. This could be extended further to include boost and timer functions for the immersion heaters. Data logging could be incorporated into the microcontroller subsystem to store generation and export information. The whole system could then be connected to the internet to allow the user remote access of the data via a computer or mobile application.

\section{ACKNOWLEDGMENT}

The lead author would also like to thank the RGU Engineering Applications staffs, in particular John Still and Steve Allardyce, for manufacturing the printed circuit boards and providing support with other practical aspects of the project. Thanks is also due to Nordri Ltd., their managing director Brian Halcrow and one of their customers George Halcrow for providing the lead author with the data to carry out the cost analysis. The authors would like to thank the Ministry of Higher Education (MOHE) of Malaysia under the grant 20160104FRGS to fund part of the activities. Any opinions findings and conclusions or recommendations expressed in this material are those of the authors and do not necessarily reflect those of MOHE of Malaysia.

\section{REFERENCES}

[1] HMRC, "Business Income Manual BIM40510," UK, 2016.

[2] DECC, "Monthly feed-in tariff commissioned installations," UK, 2016.

[3] Feed-in Tariff Ltd, "Feed-in Tariffs," 2016. [Online]. Available: http://www.fitariffs.co.uk/. [Accessed: 01Mar-2016].

[4] J. Shankleman, "Government softens feed-in tariff blow to solar and wind industries," Business Green, Haymarket, UK, Dec-2015.

[5] OFGEM, "Feed-in Tariff Annual Report 2014-15," UK, 2015.

[6] Nordri, "Why invest in wind energy?," 2016. [Online]. Available: http://www.nordri.co.uk/wind-energy/whyinvest-in-wind-energy/. [Accessed: 27-Mar-2016].

[7] DECC, "Smart meters: A guide," 2013. [Online]. Available: https://www.gov.uk/guidance/smart-metershow-they-work. [Accessed: 03-Mar-2016].

[8] EST, "Feed-in Tariff scheme," 2015. [Online]. Available:

http://www.energysavingtrust.org.uk/renewableenergy/electricity/solar-panels/feed-tariffs. [Accessed: 01-Mar-2016].

[9] Instruments Direct, "KidWind Mini Wind Turbine," $2016 . \quad$ [Online]. Available: http://www.inds.co.uk/product/kidwind-mini-windturbine/. [Accessed: 27-Mar-2016].

[10] Vernier Software \& Technology, "MINI Wind Turbine User Manual,” USA, 2015.

[11] Rapid Electronics, "Kingbright L-7113LID 5mm Red LED Low Current," 2016. [Online]. Available: https://www.rapidonline.com/electroniccomponents/kingbright-1-7113lid-5mm-red-led-lowcurrent-56-0430. [Accessed: 27-Mar-2016].

[12] Bouni, “Arduino-Pinout," GitHub, 2014. [Online]. Available: https://github.com/Bouni/Arduino-Pinout. [Accessed: 30-Mar-2016].

[13] Fdebrabander, "Arduino-LiquidCrystal-I2C-library," GitHub, 2012. [Online]. Available: https://github.com/fdebrabander/Arduino-LiquidCrystalI2C-library. [Accessed: 30-Mar-2016].

[14] S. Saini, Low Power Interconnect Design. New York, 
USA: Springer, 2015.

[15] SSE, "Get an Electricity Quote," 2016. [Online]. Available: https://www.sse.co.uk/energy/electricity\#Getan-electricity-quote. [Accessed: 31-Mar-2016].

[16] Scottish Fuels, "Personal communication on 30/3/2016," 2016.

[17] Kingspan Environmental, "KW6 748 Wind Turbine Installation Manual," UK, 2013. 